\title{
Research on the Combination Mode of Modern Product and Industrial Design under the Green Design Background
}

\author{
Liying Wu \\ Construction College of Civil Engineering ,Jiujiang University, Jiujiang City , \\ Jiangxi province, 332000 China
}

\begin{abstract}
In this paper, we conduct research on the combination mode of the modern product and the industrial design under the green design background. Our enterprises must set up the industrial design as the basis of the new mechanism, treatment of product, enterprise and market to trinity, cannot be indifferent to a certain aspect, to every aspect, to attach importance to technology, hard management talents, on the basis of industrial designers should play the role of soft energetically. Industrial design should have good adhesive property, product, enterprise and market more harmonious, more closely linked, creation of the technical performance, reasonable internal structure, a novel appearance, low production cost, a profound cultural products, for the enterprise to bring the most lucrative business profits, and make the market more prosperous more standardized. Under this background, we propose the novel combination pattern that holds special meaning.
\end{abstract}

Keywords- Combination Mode, Product and Industrial, Design, Green Design, Trend.

\section{Introduction}

Product features include material function and spiritual function. Previous multi-function products increased a lot of additional features, or superposition of a variety of functions in a product, such not only increase the manufacturing cost that also virtually increased the complexity of the products, with influence the ease of use of the products. Some additional functions use frequency is low and cause unnecessary waste, can also affect the main function of the play. Therefore, multi-function products in actual use process tend to deviate from the original intention of product design, to reach the expected purpose. Losing interest in recent years, consumers for the multi-function products, not blindly pursue products of multi-functional, but pay more attention to the quality of the products, need more material function and spiritual general function of the perfect combination of products that tend to functional specialization simplification that hopes the product operation is simple, using a fast [1-3].

Green products is the ultimate sign of green design, is the carrier of the product green degree. Green product is in its life cycle, conform to the requirements of the specific environmental protection, the ecological environment harmless or harmful is few, the highest utilization rate of resources, the least energy consumption of the product that holds following issues. (1) Green design database, knowledge base, and general green design integration tools including material performance database, database environment load, energy production and use of environmental load database, domestic and foreign laws and regulations and standard, the quantitative evaluation index system, a computer aided green design tools, etc. (2) Green energy solutions with the best design to use renewable energy, the energy efficiency, strengthen the comprehensive utilization of energy and waste heat recovery. (3) The green material design including light degradation in the environment or design technology of biodegradable materials and the development and application of natural materials. (4) Green process design through simplifying process, raw material and 
manufacturing process of auxiliary materials and by-products of comprehensive utilization and recycling that achieve low emission even zero emission [4].

It can be seen from the above these definitions, although the description of different emphases, but its essence, namely green products should be conducive to protect the ecological environment, do not produce environmental pollution or minimize the pollution, at the same time to save resources and energy, and this feature should be throughout the entire product life cycle. Therefore, based on the analysis of the above, we can give the following definition of green products for the reference: green product is in the life cycle of the whole, conform to the requirements of the specific environmental protection, ecological environment harmless or harmful is few highest utilization rates of resources and the lowest energy consumption of the product. Green design, humanized design is the center of the international design competition as is has drawn great attention of the international community, and actively in the target of products, product design and manufacturing mode, and exploration on the aspects, such as human consumption lifestyle, in the hope in near future, humans can enjoy healthy in the green environment with green life comfortable and convenient [5].

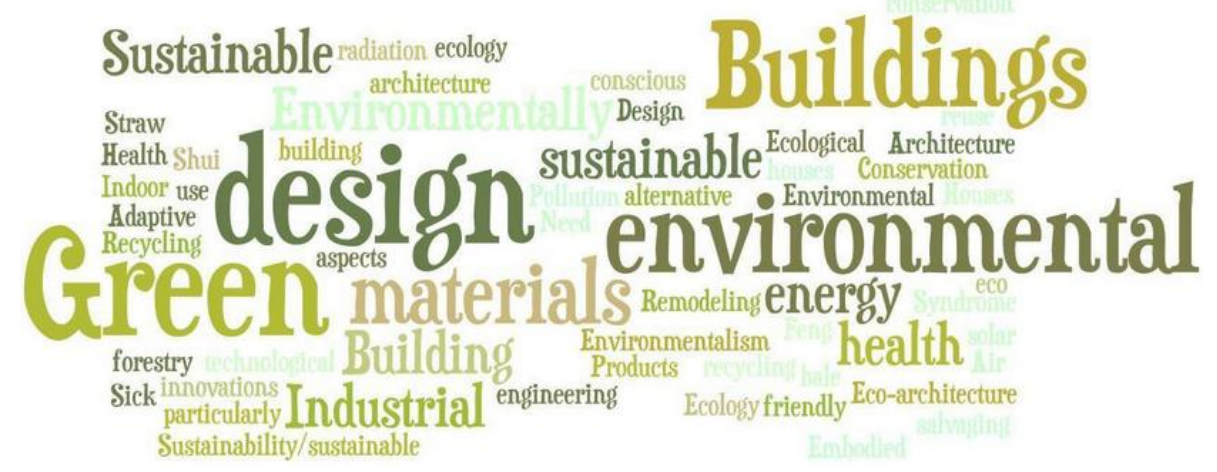

Figure 1. The Keywords of the Green Design Background

In this paper, we conduct research on the combination mode of modern product and the industrial design under the green design background. Green design with a specific goal and mission, the related subsystems, such as functional system, remove the basic recovery system, man-machine-environment system, etc., all with plan of whole, goal and mission of the system as the basis of its own goals, it is the embodiment of dialectical principle. In the later sections, we will discuss the issues in detail.

\section{The Proposed Methodology}

The Industrial Design. Industrial design is itself the product of a culture, has a special era character, it shows time, geography and people's material and cultural differences in height and public thought forms and methods of production.
It advocates people designers to create new life, new environment, to enhance the level of people's lives and the need of the public and has certain effect.

From the macro industrial design involves industrial product design, environmental design and the visual communication design with micro refers to all the mechanized mass production of industrial products. It is the combination of the situation and the function, the blend of culture phenomenon, isolated emphasize form aesthetic feeling and pure research capabilities are biased, as a result, good design is usually characterized by saving material, easy to machining, the interests of the consumers to do it for the mass production, living and the sustainable development of the tool. "Product design" in view of the problem since the industrial revolution, to explore the various values and 
coordination of the people, people and things, the relationship between man and nature in different times, the focus of the industrial design is different that have different design thought [6].
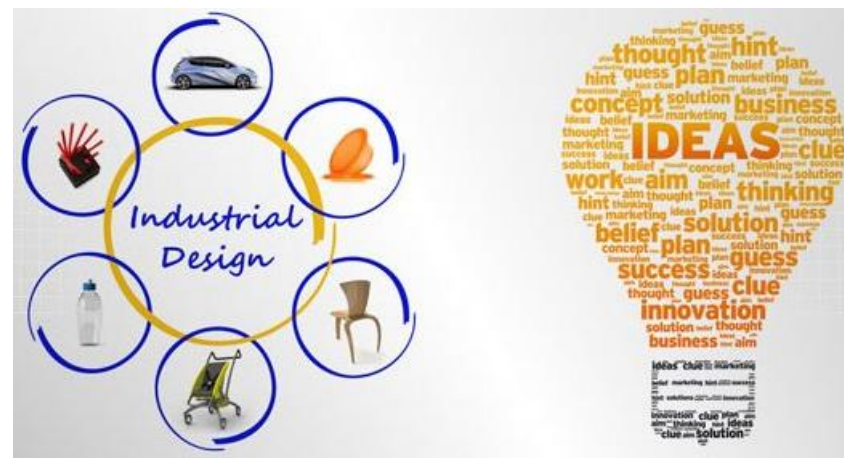

Figure 2. The General Procedures and Components of the Industrial Design

Industrial design ontology layer including design philosophy, general design principle and design of expression layer and so on three levels and it is one of the real world design abstract problem and solution, through the domain ontology construction that solve the problem of knowledge transfer, and transformation and sharing. Industrial design to solve the interaction between people and products on the one hand depends on the product itself, such as behavior logic, voice, appearance, color, material qualitative, taste, etc., includes the physical, social and cultural factors; On the other hand, relies on the user itself, such as basic needs, emotions, purpose, task, perception, expectations and ability, etc. Designer according to the design task, the demand analysis and the design analysis for design objects; According to a variety of knowledge resources and personal perception, image, etc., will demand into the form of products through the design evaluation, putting the plan into the detailed design, and go into the final product as well as into the ordinary market [7].

The Product Design. Product design has been from the past to give priority to the transition to the nowadays is given priority to with knowledge experience, as has the knowledge intensive, distributed, collaborative work, etc. In the process of product design, product design knowledge plays a key role, each step is saturated with product design knowledge, product design knowledge can guide the design of the product, the optimal way to help the designers to perform the complex product design, product design knowledge, so to speak is the soul of the whole product design.

According to the literature survey, the general procedures of the product design could be generally summarized as the follows. (1) The user factor. It is the first factor influence of the human-computer interaction design, human-computer interaction design should consider the user experience, including not only whether a user is easy to learn the human-computer interaction system, but also to master the this way of using high efficiency and low false positives, so the human-computer interaction to meet the needs of users in the first place. (2) Environmental factors. This factor also occupies the important position in human-computer interaction design. Environmental factors can be divided into both direct and indirect ways. (3) People as the main body of human-computer interaction, characteristics such as language habits, behavior, words, cultural background and cognitive level is different, such as living environment, regional characteristics, such as climate change has a great influence for the users, this is indirect effects, these differences is the human-computer interaction design must be considered.

From the perspective of the cognitive process of people, graphic thinking is a man who will further cognitive and basic creative process. Designers to record on paper with the hand, graphic through observation of the eyes and the brain thinking, identify and judgment, to give the original graphics, a feedback is sure some parts and negative parts, and improvement of the original graphics, association and imagination to produce new cognitive as evolution on the original graphics to the reciprocating constitutes the graphic thinking process. Product ecological 
definition, according to the ecosystem safety and human health standard, choose the future ecological environment features of the products. Its aim is to determine the ecological environment of the product attributes, make the whole product commercial value can contain ecological environment value. Affect the product competition ability of the ecological environment parameters. Parameters of environment of the need to consider the choice of consumer expectations, the environment of focal point of the competition, enterprise's long-term environmental policy and strategy, environmental parameters and other parameters of balance [8].

\section{The Green Design Concepts and Principles.} According to the theory of the product conceptual design, the design process is described as the function of the customer demand driven domain and behavior domain and structure domain mapping between the transformations. Green design unit will functions information, behavior general structure information and attribute information green four pack integrated, from function domain, behavior domain, domain and green design domain structure four aspects describe the concept of basic green product design process. (1) Ecological sustainable. Continue to change simply the pursuit of economic growth, to ignore the traditional development mode and model of ecological environment protection, maintain the integrity of life support system, maintaining biodiversity, protection and the preservation of human atmosphere, fresh water, sea, land, forests and other natural resources from pollution, and wanton abuse, active control and recovery has been destroyed and pollution of environment. (2) Social sustainable. Social continued to improve the quality of human life, for the purpose of the actively promote civilian society, fair, safe and healthy direction. (3) Sustained. The economy continues to require through the basic adjustment of industrial structure and application of high and new technology development, transformation of the mode of the economic growth, improve quality, optimize configuration, save energy and reduce consumption.

Implemented in various related fields, through the design behavior let rationality has technology advanced, economic, and environmental friendly products can meet the reasonable demands of the people, and to guarantee the demand of security and continuity, between people, society, environment to establish a coordinated development mechanism and the core relationship between the ecological balance as all of the attributes from the pursuit of the green design products are harmless in the earth's ecological evolution of universal ethics, to achieve the life of the product is conducive to the ultimate goal of the human long-term survival, its content is beyond the scope of material product design, it has been associated with the significance of economic foundation and superstructure of human society.

The Product and Industrial Design Combination. Industrial design as an effective tool to achieve product differentiation, to the enterprise to win an increasingly important role in the consumer demand in order to win the market through industrial design, can enhance product differentiation, to help enterprises to carry out the strategy of product differentiation. Industrial design in the form of the product differentiation mainly include two aspects: one is the appearance design can realize product differentiation, when similar performance and price, while the users are more willing to choose to have aesthetic value of products; The second is the improvement of the interface can enhance product stability and ease of use and improve the user experience [9].

Each product design, should first establish the user model. It is the designer has knowledge of the user. The semiotics is used for product design, first of all, also to build user semantic model, it mainly contains the basic user experience with knowledge to the operation of the product, the words used to operate the product use, develop 
products operating logic of thought. The action of these words content constitutes the user semantic model. This user semantic model is the main basis of stylist, to make the product of basic man-machine interface provides the operating conditions, and accurately expresses the meaning of it. It was this yearning and pursuit of harmony, become a strong driving force to promote the development of enterprise product development. Industrial design is the bridge of high and new technology and daily life that are of businesses and consumers. At the same time, industrial design also has the market competition, coupling technology and market, to create the good commodities and the media, pulled goods, create high value-added role, in order to create core new markets, promote the market segmentation, reduce the cost. In the fierce competition of economic globalization, industrial design is becoming the important resources in the enterprise management.

Industrial design can become the important resource of enterprises, promote the development of the social economy, mainly manifested in it not only satisfy the people's growing material needs, and also satisfy people's spiritual general needs. Industrial designers form shaping is a long-term accumulation process, at the same time but also the process of a rolling development. It should keep pace with the times, and in line with the native culture, formed a kind of interactive relationship. In reflecting the design culture at the same time, promote innovation of design culture, formed the tacit understanding in the process of the interaction. The combination of the science and technology and art is in constant progress and improve, a new concept of design pattern will along with the development of the times, science and technology and the development of the arts and humanities and update. Industrial design should be people-centered, emphasizing the materials, the perfect combination of visual and function, is the unity of modern science and technology and aesthetics. After the material conditions are met, mental factor is very important in the pursuit of "beauty", no one wants around the daily necessities is a pile of steel, machine or a monster, but is ready to use, and happy to see bring convenient products. A product first should be practical, yet only weight function of the product is flawed, and discrepancy and the demand for utility of modern people. Designer's task is to find all kinds of factors of beauty and function of organic connection, the design is practical, and conforms to way of beauty products.

\section{Conclusion}

In this paper, we conduct research on the combination mode of the modern product and the industrial design under the green design background. With the acceleration of economic integration, the core of products on the international market competition has been to design competition on the basis of the development of science and the technology. Mature technology is more and more countries, various enterprises apply to identity, and product, the brand differentiation is mainly thanks to the product innovation. Innovation is the motive force of sustainable development, is the core of industrial design and source. Our research combines the concept of green design to propose the combination mode of the modern product and the industrial design that is innovative.

\section{References}

[1] Tseng, Ming-Lang, Raymond R. Tan, and Anna Bella Siriban-Manalang. "Sustainable consumption and production for Asia: sustainability through green design and practice." Journal of Cleaner Production 40 (2013): 1-5.

[2] Liao, Chi - Shun, Kuo - Ren Lou, and Ching - Tzu Gao. "Sustainable Development of Electrical and Electronic Equipment: User - driven Green Design for 
Cell Phones." Business Strategy and the Environment 22.1 (2013): 36-48.

[3] Zheng, Jun, et al. "Variable fidelity metamodel-based analytical target cascading method for green design." The International Journal of Advanced Manufacturing Technology (2013): 1-14.

[4] Tobias, Leanne, and George Vavaroutsos. Retrofitting Buildings to be Green and Energy-Efficient: Optimizing Building Performance, Tenant Satisfaction, and Financial Return. Chicago, IL, USA: Urban Land Institute, 2012.

[5] Kembel, Steven W., et al. "Architectural design drives the biogeography of indoor bacterial communities." PLoS One 9.1 (2014): e87093.
[6] Bryde, David, Martí Broquetas, and Jürgen Marc Volm. "The project benefits of building information modelling (BIM)." International journal of project management 31.7 (2013): 971-980.

[7] Chang, Chun-Chih, et al. "Ultra-selective cycloaddition of dimethylfuran for renewable p-xylene with H-BEA." Green Chemistry 16.2 (2014): 585-588.

[8] Tucker, Joan S., et al. "Neighborhood characteristics and the initiation of marijuana use and binge drinking." Drug and alcohol dependence 128.1 (2013): 83-89.

[9] YaDeau, Jacques T., et al. "Lumbar plexus blockade reduces pain after hip arthroscopy: a prospective randomized controlled trial." Anesthesia \& Analgesia 115.4 (2012): 968-972. 